\title{
Computing Markov-Perfect Optimal Policies in Business-Cycle Models*
}

\author{
Richard Dennis ${ }^{\dagger}$ \\ University of Glasgow
}

\author{
Tatiana Kirsanova \\ University of Glasgow
}

January 2015

\begin{abstract}
Time-inconsistency is an essential feature of many policy problems (Kydland and Prescott, 1977). This paper presents and compares three methods for computing Markov-perfect optimal policies in stochastic nonlinear business cycle models. The methods considered include value function iteration, generalized Euler-equations, and parameterized shadow prices. In the context of a business cycle model in which a fiscal authority chooses government spending and income taxation optimally, while lacking the ability to commit, we show that the solutions obtained using value function iteration and generalized Euler equations are somewhat more accurate than that obtained using parameterized shadow prices. Among these three methods, we show that value function iteration can be applied easily, even to environments that include a risk-sensitive fiscal authority and/or inequality constraints on government spending. We show that the risk-sensitive fiscal authority lowers government spending and income-taxation, reducing the disincentive households face to accumulate wealth.
\end{abstract}

Keywords: Markov-Perfect Policy, Time-Consistency, Fiscal Policy

JEL Classification: E62, C61, C63.

\footnotetext{
${ }^{*}$ We would like to thank the Editor, two anonymous referees, and participants at the 2012 Second VUW Macro Workshop, Wellington, for comments.

${ }^{\dagger}$ Address for Correspondence: Adam Smith Business School, University of Glasgow, Main Building, University Avenue, Glasgow G12 8QQ; email: richard.dennis@glasgow.ac.uk.
} 


\section{Introduction}

Governments are confronted routinely with important policy decisions, not least with decisions regarding spending and taxation (i.e., fiscal policy) and about how to set a policy interest rate (i.e., monetary policy). Following Kydland and Prescott (1977) it is now well-known that, when private agents are forward-looking and rational, optimal policies are (invariably) not timeconsistent and that time-consistent policies are (invariably) not optimal. Absent a commitment technology, attention focuses naturally on policies that are time-consistent or, more specifically, on equilibria that are Markov-perfect and this focus has led to a large literature on "discretionary" policymaking. While there are notable exceptions, the vast bulk of this literature computes equilibrium using what is essentially linear-quadratic dynamic programming with the policy problem approximated to have the required linear constraints and quadratic objective. Although some policy problems can conceivably be well-approximated by linear constraints and second-order accurate welfare approximations, such as policy problems for which the steady state is efficient, and for other problems, such as those where the model has many state variables, only linear-quadratic methods may be feasible, for many interesting problems, such as problems involving distortionary taxes and/or imperfect competition, first-order accuracy cannot be obtained through linear-quadratic methods. Moreover, some model characteristics, like occasionally binding constraints, call out for nonlinear solution methods even when the policy objective is quadratic (Adam and Billi, 2007; Nakata, 2012). Fortunately, it is becoming increasingly feasible to analyze discretionary policymaking without turning to the linear-quadratic toolkit.

In this paper we present and compare three strategies for computing Markov-perfect optimal policies in nonlinear stochastic business cycle models. These strategies apply to economies populated by a large number of atomistic private agents and by a benevolent government, tasked with conducting policy in order to maximize the welfare of the representative household. The solution strategies include value function iteration, policy function iteration on generalized Euler equations, and parameterized shadow prices. To illustrate the three strategies we apply them to the canonical dynamic model of fiscal policy taken from Klein, Krusell, and Ríos-Rull (2008), augmented to include an transitory aggregate technology shock and extended to allow for capital depreciation (as per Ambler and Pelgrin, 2010). In this model, government spending provides households with utility and the fiscal authority's problem is to choose government spending optimally, subject to a balanced-budget constraint, while lacking both a commitment technology 
and the ability to impose lump-sum taxes. This balanced-budget fiscal policy model provides the ideal environment in which to illustrate the methods because this model, or closely related models, have been studied by Stockman (2001), Benhabib and Rustichini (1997), Klein and Ríos-Rull (2003), Ortigueira (2006), Klein, Krusell, and Ríos-Rull (2008), and Ambler and Pelgrin (2010). However, with the exception of Ambler and Pelgrin (2010), each of these studies has looked only at deterministic specifications and/or focused only on the model's steady state behavior. ${ }^{1}$

For the canonical fiscal policy model we find that value function iteration and the generalized Euler equations solution method, both employing Chebyshev polynomials for function approximation and Gauss-Hermite quadrature for integration, perform well and are notably more accurate in terms of Euler-equation errors than the parameterized shadow prices solution approach, which is based on parameterized expectations and uses Monte Carlo integration. We extend the canonical model to allow for a risk-sensitive fiscal authority and for an inequality constraint on government spending as a share of output and show how the equilibrium of these models can be computed easily, and relatively accurately, using the value function iteration solution method. We show that the risk-sensitive fiscal authority cuts government spending in order to reduce income taxation and thereby mitigate the disincentive on household capital accumulation.

Our paper is related to several others. In particular, we take our main model - a balancedbudget fiscal policy problem - from Ambler and Pelgrin (2010), who show how a method of parameterized expectations can be used to compute its time-consistent equilibrium. Our use of Chebyshev polynomials for approximating functions is shared by a number of studies, including Ortigueira (2006), Niemann, Pichler, and Sorger (2008, 2009), Ortigueira, Pereira, and Pichler (2012), and Anderson, Kim, and Yun (2010). Our paper is also related to the important literature on discretionary policymaking in linear-quadratic models, and to the computational strategies of Kydland and Prescott (1977), Oudiz and Sachs (1985), Currie and Levine (1985, 1993), Backus and Driffill (1986), Söderlind (1999), and Dennis (2007).

The remainder of the paper is organized as follows. Section 2 describes a simple balancedbudget business cycle model of fiscal policy. This model is interesting in its own right and usefully serves as a vehicle for illustrating and comparing the various solution strategies. Section 3 presents the three solution strategies. Section 4 applies the various solution strategies to solve

\footnotetext{
${ }^{1}$ Benhabib and Rustichini (1997), Domínguez (2007), and Ortigueira, Pereira, and Pichler (2012) consider related models in which the fiscal authority's balanced-budget restriction is relaxed. But these studies, too, focus on deterministic models.
} 
the fiscal policy model for its Markov-perfect equilibrium. Section 5 shows how features such as occasionally binding constraints and risk-sensitivity can be accommodated. Section 6 discusses computation times and the application of these methods to larger models. Section 7 offers concluding remarks.

\section{The model}

We consider a production economy populated by a unit-mass of identical atomistic households, a unit-mass of identical atomistic firms, and a fiscal authority. Firms rent capital and hire labor from households and use these inputs to produce goods that are sold to households and the fiscal authority. Goods sold to the fiscal authority are transformed costlessly into a government consumption good while those sold to households are either consumed or used to augment the capital stock. The fiscal authority taxes household income, using the revenue to finance the provision of the government consumption good. Markets are assumed to be perfectly competitive. This model follows Ambler and Pelgrin (2010) and extends Klein, Krusell, and Ríos-Rull (2008).

\section{$2.1 \quad$ Households}

Households own the capital stock. They receive income by renting their capital and supplying their labor to firms at prices $r_{t}$ and $w_{t}$, respectively. After paying income tax, households use their remaining income to purchase goods, which they use to offset capital-depreciation, to invest in their capital stock, and to consume. The representative household's lifetime utility function is described by

$$
\mathrm{E} \sum_{t=0}^{\infty} \beta^{t} u\left(c_{t}, G_{t}\right),
$$

where $\beta \in(0,1)$ is the discount factor, $c_{t}$ denotes private consumption, $G_{t}$ denotes government consumption goods, and the momentary utility function $u\left(c_{t}, G_{t}\right)$ is assumed to be strictly increasing, strictly concave, twice continuously differentiable, and to satisfy the Inada (1963) conditions. The capital owned by the representative household evolves over time according to

$$
k_{t+1}+c_{t}=k_{t}+\left(1-\tau_{t}\right)\left[\left(r_{t}-\delta\right) k_{t}+w_{t}\right]
$$

where $\delta \in(0,1)$ is the depreciation rate, $\tau_{t}>0$ is the tax rate applied to household income (with a tax-allowance for capital-depreciation), and $k_{t}$ is the household's stock of capital as of the 
beginning of period $t$. Households maximize their expected lifetime utility, (1), subject to their flow-budget constraint, (2), taking prices, taxes, and government consumption goods as given.

\section{$2.2 \quad$ Firms}

Our stand-in aggregate firm employs capital and labor to produce output according to the neoclassical production technology

$$
Y_{t}=e^{z_{t}} F\left(K_{t}, 1\right)=e^{z_{t}} F\left(K_{t}\right)
$$

where $Y_{t}$ represents aggregate output, $K_{t}$ denotes the aggregate capital stock as of the beginning of period $t$, and $z_{t}$ is an aggregate technology shock that obeys the stochastic process

$$
z_{t+1}=\rho z_{t}+\epsilon_{t+1}
$$

where $\rho \in(0,1)$ and $\epsilon_{t} \sim i . i . d .\left[0, \sigma_{\epsilon}^{2}\right]$.

Markets for capital and labor are perfectly competitive and clear at the prices

$$
\begin{aligned}
r_{t} & =e^{z_{t}} F_{K}\left(K_{t}\right), \\
w_{t} & =e^{z_{t}} F\left(K_{t}\right)-e^{z_{t}} F_{K}\left(K_{t}\right) K_{t},
\end{aligned}
$$

respectively, with the stand-in firm making zero-profits in equilibrium.

\subsection{Fiscal authority}

The fiscal authority cannot impose lump-sum taxes, but receives revenue by taxing household income at marginal rate $\tau_{t}$. These tax revenues are used to purchase goods that are costlessly transformed into government consumption goods and provided to households at zero unit-cost. The fiscal authority has no outstanding liabilities and cannot issue bonds. As a consequence, the fiscal authority's decisions about taxation and the provision of the public good, decisions made to maximize the welfare of the representative household, are constrained by the balanced-budget condition

$$
G_{t}=\tau_{t}\left[\left(r_{t}-\delta\right) K_{t}+w_{t}\right]
$$

where $G_{t}$ denotes aggregate government consumption. 


\subsection{Information, timing, and aggregation}

With the current realization for the aggregate technology given by $z_{t}$, we denote the history of realizations for aggregate technology up to and including period $t$ by $z^{t}=\left\{z_{i}\right\}_{i=0}^{t}$. Similarly, using $\mathbf{x}_{t}=\left[\begin{array}{lll}z_{t} & k_{t} & K_{t}\end{array}\right]^{\prime}$ to denote the economy's state at the beginning of period $t$, we assume that at the beginning of period $t$ all agents are endowed with the information set given by the history $\mathbf{x}^{t}$. After entering period $t$, and having observed $\mathbf{x}^{t}$, the fiscal authority, firms, and households make their decisions simultaneously. This timing protocol is also considered by Cohen and Michel (1988), Ortigueira (2006), and Ambler and Pelgrin (2010) and is relatively common in the literature on optimal fiscal policy. ${ }^{2}$ Our assumptions that all households and all firms are identical and that they are of unit-mass implies that $K_{t}=k_{t}$ and $C_{t}=c_{t}$ in aggregate.

\section{Solving for Markov-perfect optimal policy}

In this section we present three ways to solve this fiscal-policy model for a Markov-perfect equilibrium. More generally, however, this model is quite representative of the fiscal- and monetarypolicy problems that we are interested in, and the solution methods presented here can be applied quite broadly to these problems. As we shall see, the value function iteration method that we describe can also be applied with relative ease to more sophisticated policy problems, ones involving features such as Epstein-Zin preferences, risk-sensitive preferences, and/or occasionally binding constraints.

\subsection{Value function iteration}

The problem facing the representative household can be represented by the Bellman equation

$$
v\left(z_{t}, k_{t}, K_{t}\right)=\max _{c_{t}, k_{t+1}}\left\{u\left(c_{t}, G_{t}\right)+\beta \mathrm{E}_{t}\left[v\left(z_{t+1}, k_{t+1}, K_{t+1}\right)\right]\right\}
$$

with the constraints given by the laws-of-motion for household-level and aggregate capital, respectively,

$$
\begin{aligned}
k_{t+1} & \left.=k_{t}+\left(1-\frac{G_{t}}{e^{z_{t}} F\left(K_{t}\right)-\delta K_{t}}\right)\left[\left(e^{z_{t}} F_{K}\left(K_{t}\right)-\delta\right) k_{t}+e^{z_{t}} F\left(K_{t}\right)-e^{z_{t}} F_{K}\left(K_{t}\right) K_{t}\right]-c_{k}, 9\right) \\
K_{t+1} & =(1-\delta) K_{t}+e^{z_{t}} F\left(K_{t}\right)-C_{t}-G_{t} .
\end{aligned}
$$

\footnotetext{
${ }^{2}$ In the monetary policy literature it is more common to assume that the government has a first-mover advantage within the period. See for example Clarida, Galí, and Gertler (1999) and Woodford (2003). Martin (in press) uses a model related to Klein, Krusell, and Ríos-Rull (2008) to study the effect on welfare of different timing protocols.
} 
taking $G_{t}$ and $C_{t}$ as given, and with the initial conditions $z_{t}>0$ and $k_{t}=K_{t}>0$, known. Notice that (5) and (6) have been used so that (9) does not contain prices. Combining the first-order condition with respect to consumption, $c_{t}$, and the Benveniste and Scheinkman (1979) condition, and aggregating across identical households gives the consumption-Euler equation

$$
u_{c}\left(C_{t}, G_{t}\right)=\beta \mathrm{E}_{t}\left\{u_{c}\left(C_{t+1}, G_{t+1}\right)\left[1+\left(1-\frac{G_{t+1}}{e^{z_{t+1}} F\left(K_{t+1}\right)-\delta K_{t+1}}\right)\left(e^{z_{t+1}} F_{K}\left(K_{t+1}\right)-\delta\right)\right]\right\} .
$$

The fiscal authority's problem is described by the Bellman equation

$$
V\left(z_{t}, K_{t}\right)=\max _{G_{t}, K_{t+1}}\left\{u\left(C_{t}, G_{t}\right)+\beta \mathrm{E}_{t}\left[V\left(z_{t+1}, K_{t+1}\right)\right]\right\}
$$

with the constraints given by (10) with the initial conditions $z_{t}>0$ and $K_{t}>0$, known.

\subsection{Equilibrium}

A Markov-perfect Nash equilibrium for this model is a collection of household decision rules, $\left\{c\left(z_{t}, k_{t}, K_{t}\right), k\left(z_{t}, k_{t}, K_{t}\right)\right\}$, a collection of aggregate decision rules, $\left\{C\left(z_{t}, K_{t}\right), G\left(z_{t}, K_{t}\right), K\left(z_{t}, K_{t}\right)\right\}$, and a collection of value functions, $\left\{v\left(z_{t}, k_{t}, K_{t}\right), V\left(z_{t}, K_{t}\right)\right\}$, such that

1. The collection $\left\{v\left(z_{t}, k_{t}, K_{t}\right), c\left(z_{t}, k_{t}, K_{t}\right), k\left(z_{t}, k_{t}, K_{t}\right)\right\}$ solves the household's decision problem described by the Bellman equation, (8), and the constraints, (9) and (10).

2. The collection $\left\{V\left(z_{t}, K_{t}\right), C\left(z_{t}, K_{t}\right), K\left(z_{t}, K_{t}\right), G\left(z_{t}, K_{t}\right)\right\}$ solves the fiscal authority's decision problem described by the Bellman equation, (12), and the constraint, (10).

3. $k_{t}=K_{t}, C\left(z_{t}, K_{t}\right)=c\left(z_{t}, K_{t}, K_{t}\right)$, and $k\left(z_{t}, K_{t}, K_{t}\right)=K\left(z_{t}, K_{t}\right)$.

As we describe later, to solve numerically the fiscal authority's problem we conjecture functions for aggregate consumption, $C\left(z_{t}, K_{t}\right)$, aggregate government spending, $G\left(z_{t}, K_{t}\right)$, and the value function, $V\left(z_{t}, K_{t}\right)$. Based on these conjectured functions and the law-of-motion for aggregate capital, we solve the fiscal authority's problem using a hill-climber, obtaining updates for $G\left(z_{t}, K_{t}\right)$ and $V\left(z_{t}, K_{t}\right)$, the former of which, when combined with (11) delivers an update for $C\left(z_{t}, K_{t}\right)$. Iterating to convergence we arrive at a Markov perfect equilibrium for this policy problem. 


\subsection{Generalized Euler equations}

To solve the model for a Markov-perfect equilibrium using generalized Euler equations, we return to the fiscal authority's decision problem, which is described by the Bellman equation

$$
V\left(z_{t}, K_{t}\right)=\max _{G_{t}, K_{t+1}}\left\{u\left(C_{t}, G_{t}\right)+\beta \mathrm{E}_{t}\left[V\left(z_{t+1}, K_{t+1}\right)\right]\right\}
$$

and the constraint

$$
K_{t+1}=(1-\delta) K_{t}+e^{z_{t}} F\left(K_{t}\right)-C_{t}-G_{t}
$$

The first-order condition with respect to $G_{t}$ gives

$$
u_{G}\left(C_{t}, G_{t}\right)=\beta \mathrm{E}_{t}\left[V_{K}\left(z_{t+1}, K_{t+1}\right)\right],
$$

while the Benveniste-Scheinkman condition yields

$$
\begin{aligned}
V_{K}\left(z_{t}, K_{t}\right)= & u_{C}\left(C_{t}, G_{t}\right) C_{K}\left(z_{t}, K_{t}\right)+u_{G}\left(C_{t}, G_{t}\right) G_{K}\left(z_{t}, K_{t}\right) \\
& +\beta \mathrm{E}_{t}\left[V_{K}\left(z_{t+1}, K_{t+1}\right)\right]\left[1-\delta+e^{z_{t}} F_{K}\left(K_{t}\right)-C_{K}\left(z_{t}, K_{t}\right)-G_{K}\left(z_{t}, K_{t}\right)\right]
\end{aligned}
$$

and together (15) and (16) imply the generalized Euler equation

$$
\begin{aligned}
u_{G}\left(C_{t}, G_{t}\right)= & \beta \mathrm{E}_{t}\left[\left(u_{C}\left(C_{t+1}, G_{t+1}\right)-u_{G}\left(C_{t+1}, G_{t+1}\right)\right) C_{K}\left(z_{t+1}, K_{t+1}\right)\right] \\
& +\beta \mathrm{E}_{t}\left\{u_{G}\left(C_{t+1}, G_{t+1}\right)\left[1-\delta+e^{z_{t+1}} F_{K}\left(K_{t+1}\right)\right]\right\},
\end{aligned}
$$

which is "generalized" because it contains both the level and the derivative of $C\left(z_{t+1}, K_{t+1}\right)$.

To solve for a Markov-perfect equilibrium one needs to solve the system consisting of (14), (17), and (11) from the household's problem, with the process for the aggregate technology shock given by (4). To solve this system we conjecture functions for aggregate consumption, $C\left(z_{t}, K_{t}\right)$, aggregate government spending, $G\left(z_{t}, K_{t}\right)$, and iterate on the system until a fixed-point is reached.

\subsection{Parameterized shadow prices}

To solve the model for a time-consistent equilibrium using parameterized shadow prices (Ambler and Pelgrin, 2010), we formulate the household's problem in terms of a Lagrangian

$\mathrm{E} \sum_{t=0}^{\infty} \beta^{t}\left[\begin{array}{c}u\left(c_{t}, G_{t}\right) \\ +\phi_{t}\left(k_{t}+\left(1-\frac{G_{t}}{e^{z} F\left(K_{t}\right)-\delta K_{t}}\right)\left[\left(e^{z_{t}} F_{K}\left(K_{t}\right)-\delta\right) k_{t}+e^{z_{t}} F\left(K_{t}\right)-e^{z_{t}} F_{K}\left(K_{t}\right) K_{t}\right]-c_{t}-k_{t+1}\right)\end{array}\right]$, 
and derive the first-order conditions with respect to $c_{t}, k_{t+1}$, and $\phi_{t}$, which after aggregating across identical households (implying $\Phi_{t}=\phi_{t}$ ) are, respectively,

$$
\begin{aligned}
u_{C}\left(C_{t}, G_{t}\right) & =\Phi_{t} \\
\Phi_{t} & =\beta \mathrm{E}_{t}\left\{\left[1+\left(1-\frac{G_{t+1}}{e^{z_{t+1}} F\left(K_{t+1}\right)-\delta K_{t+1}}\right)\left(e^{z_{t+1}} F_{K}\left(K_{t+1}\right)-\delta\right)\right] \Phi_{t+1}\right\} \\
K_{t+1} & =K_{t}+\left(1-\frac{G_{t}}{e^{z_{t}} F\left(K_{t}\right)-\delta K_{t}}\right)\left[\left(e^{z_{t}} F_{K}\left(K_{t}\right)-\delta\right) k_{t}+e^{z t} F\left(K_{t}\right)-e^{z_{t}} F_{K}\left(K_{t}\right) K_{t}\right]-\left(\mathscr{Q}_{t}\right)
\end{aligned}
$$

Now recognizing that the shadow price $\Phi_{t}$ will be a function of only $z_{t}$ and $K_{t}$ in a simultaneousmove time-consistent equilibrium, the fiscal authority's problem is formulated using the Lagrangian

$$
\mathrm{E} \sum_{t=0}^{\infty} \beta^{t}\left\{\begin{array}{c}
u\left(C_{t}, G_{t}\right)+\Xi_{t}\left(u_{C}\left(C_{t}, G_{t}\right)-\Phi\left(z_{t}, K_{t}\right)\right) \\
+\Psi_{t}\left[(1-\delta) K_{t}+e^{z_{t}} F\left(K_{t}\right)-C_{t}-G_{t}-K_{t+1}\right]
\end{array}\right\} .
$$

The first-order conditions from the fiscal authority's decision problem yield

$$
\begin{aligned}
u_{C}\left(C_{t}, G_{t}\right) & =\Psi_{t}-u_{C C}\left(C_{t}, G_{t}\right) \Xi_{t}, \\
u_{G}\left(C_{t}, G_{t}\right) & =\Psi_{t}-u_{C G}\left(C_{t}, G_{t}\right) \Xi_{t}, \\
\Psi_{t} & =\beta \mathrm{E}_{t}\left[\left(1-\delta+e^{z_{t+1}} F_{K}\left(K_{t+1}\right)\right) \Psi_{t+1}-\Phi_{K}\left(z_{t+1}, K_{t+1}\right) \Xi_{t+1}\right], \\
u_{C}\left(C_{t}, G_{t}\right) & =\beta \mathrm{E}_{t}\left\{\left[1+\left(1-\frac{G_{t+1}}{e^{z_{t+1}} F\left(K_{t+1}\right)-\delta K_{t+1}}\right)\left(e^{z_{t+1}} F_{K}\left(K_{t+1}\right)-\delta\right)\right] u_{C}\left(C_{t+1}, G_{t+1} \gamma_{2} 6 .\right)\right. \\
K_{t+1} & =(1-\delta) K_{t}+e^{z_{t}} F\left(K_{t}\right)-C_{t}-G_{t} .
\end{aligned}
$$

The time-consistent equilibrium is now obtained by solving (23)-(27), and (4) using parameterized expectations (Marcet and Lorenzoni, 1999), to approximate the expectation terms in (25) and (26).

\section{Solving the model}

In this section we solve the model presented in Section 2 using the three methods discussed in Section 3. For this exercise, we assume that the representative household's momentary utility function is of the additively separable form

$$
u\left(c_{t}, G_{t}\right)=\frac{c_{t}^{1-\sigma}-1}{1-\sigma}+\mu \frac{G_{t}^{1-\eta}-1}{1-\eta},
$$

where $\{\sigma, \eta, \mu\}>0$, and that the production function is

$$
Y_{t}=e^{z_{t}} K_{t}^{\alpha},
$$


where $\alpha \in(0,1)$.

Our parameterization of the model follows Ambler and Pelgrin (2010) and is summarized in Table $1 .^{3}$

\begin{tabular}{l|c|l}
\hline \hline \multicolumn{3}{c}{ Table 1: Benchmark Parameterization } \\
\hline Parameter & Value & Interpretation \\
\hline$\beta$ & 0.987 & Household discount factor \\
$\sigma$ & 1.000 & Utility curvature of private consumption \\
$\mu$ & 0.300 & Utility weight on government services \\
$\eta$ & 1.000 & Utility curvature of government services \\
$\alpha$ & 0.300 & Capital-share of output \\
$\delta$ & 0.050 & Depreciation rate \\
$\rho$ & 0.950 & Persistence of technology shock \\
$\sigma_{\epsilon}$ & 0.030 & Standard deviation of technology shock \\
\hline \hline
\end{tabular}

To compute the Markov-perfect equilibrium using value function iteration (VFI) and generalized Euler equations (GEE) we use Chebyshev polynomials to approximate the conjectured functions. In the case of GEE, the procedure requires introducing polynomials to approximate the decision rules for consumption, $C\left(z_{t}, K_{t}\right)$, and government spending, $G\left(z_{t}, K_{t}\right)$, while VFI requires, in addition, a polynomial to approximate the value function, $V\left(z_{t}, K_{t}\right)$. For a generic function, $X\left(z_{t}, K_{t}\right)$, these polynomial approximations take the form

$$
X\left(z_{t}, K_{t}\right) \simeq \sum_{j=1}^{n^{z}} \sum_{i=0}^{n^{k}} w_{i j} \Gamma_{i}\left(K_{t}\right) \Gamma_{j}\left(z_{t}\right)
$$

where $\Gamma_{i}\left(K_{t}\right)$ represents the $i$ 'th term of the Chebyshev polynomial in aggregate capital, $\Gamma_{j}\left(z_{t}\right)$ represents the $j$ 'th term of the Chebyshev polynomial in aggregate technology, $n^{k}$ and $n^{z}$ represent the orders of the Chebyshev polynomials, and $w_{i j}$ represents the Chebyshev weights.

For VFI, at each node for capital and technology we use a Newton-based hill climber to solve

$$
V\left(z_{t}, K_{t}\right)=\max _{G_{t}, K_{t+1}}\left[\frac{C\left(z_{t}, K_{t}, G_{t}\right)^{1-\sigma}-1}{1-\sigma}+\mu \frac{G_{t}^{1-\eta}-1}{1-\eta}+\beta \mathrm{E}_{t}\left[V\left(z_{t+1}, K_{t+1}\right)\right]\right],
$$

subject to ${ }^{4}$

$$
K_{t+1}=(1-\delta) K_{t}+e^{z_{t}} K_{t}^{\alpha}-C\left(z_{t}, K_{t}, G_{t}\right)-G_{t},
$$

\footnotetext{
${ }^{3}$ There is a typo in Ambler and Pelgrin (2010, Table 1) in which their depreciation rate is reported to be 0.025.

${ }^{4}$ When optimizing the Bellman equation we substitute the constraint into the continuation value and maximize with respect to $G_{t}$.
} 
computing conditional expectations using Gauss-Hermite quadrature. This maximization yields the policy rule for government spending, $G\left(z_{t}, K_{t}\right)$, and the associated value function, $V\left(z_{t}, K_{t}\right)$. From $G\left(z_{t}, K_{t}\right)$ and $C\left(z_{t}, K_{t}, G_{t}\right)$ we compute $C\left(z_{t}, K_{t}\right)$. For GEE, at each node for capital and technology we use direct iteration over (14), (17), and (11), again computing conditional expectations using Gauss-Hermite quadrature. For both VFI and GEE, the weights in the Chebyshev polynomials are constructed through Chebyshev-regression with capital and technology constrained to the intervals $K_{t} \in[5,15]$ and $z_{t} \in\left[-\frac{3 \sigma_{\epsilon}^{2}}{1-\rho^{2}}, \frac{3 \sigma_{\epsilon}^{2}}{1-\rho^{2}}\right]$. To solve the model under its benchmark parameterization we set $n^{z}=6$ and $n^{k}=9$, and use 50 Chebyshev nodes for the capital stock and 21 Chebyshev nodes for aggregate technology. For the quadrature step, 21 Gauss-Hermite nodes were used.

For the parameterized shadow prices (PSP) method we parameterized the shadow prices according to ${ }^{5}$

$$
\begin{aligned}
& \Phi\left(z_{t}, K_{t}\right) \simeq \widetilde{\Phi}\left(z_{t}, K_{t}\right)=e^{\left(\lambda_{1}+\lambda_{2} \ln \left(K_{t}\right)+\lambda_{3} z_{t}\right)} \\
& \Psi\left(z_{t}, K_{t}\right) \simeq \widetilde{\Psi}\left(z_{t}, K_{t}\right)=e^{\left(\theta_{1}+\theta_{2} \ln \left(K_{t}\right)+\theta_{3} z_{t}\right)}
\end{aligned}
$$

and performed Monte Carlo integration using 1,000,000 simulated observations.

To evaluate the accuracy of each solution we computed the Euler-equation errors (Judd, 1992)

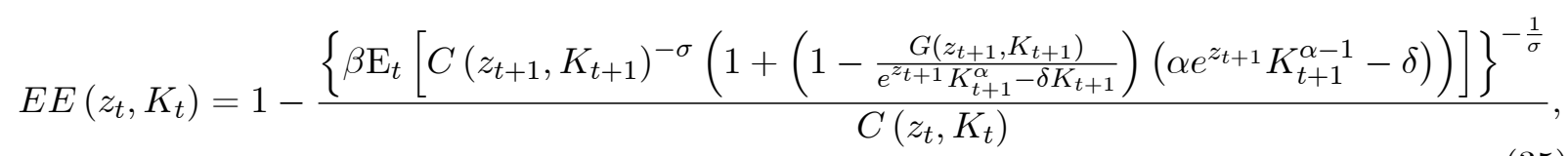

employing uniform grids for capital and technology over their intervals and using 1000 grid-points in each dimension.

\subsection{Results comparison}

Table 2 presents some summary statistics from the solutions; the stochastic steady state values were computing by simulating data (1,000,000 observations) from each solution and taking the unconditional mean.

\footnotetext{
${ }^{5}$ Equations (33) and (34) describe Ambler and Pelgrin's first-order approximation; they also consider a secondorder approximation, obtaining very similar results.
} 


\begin{tabular}{l|c|c|c}
\hline \hline \multicolumn{4}{c}{ Table 2: Stochastic steady state solutions and accuracy } \\
\hline \multicolumn{1}{c}{ Variable } & VFI & GEE & PSP \\
\hline Output & 1.92262 & 1.92262 & 1.92262 \\
Consumption & 1.15960 & 1.15960 & 1.15959 \\
Government spend. & 0.32907 & 0.32906 & 0.32910 \\
Investment & 0.43396 & 0.43396 & 0.43394 \\
Capital & 8.67923 & 8.67921 & 8.67889 \\
\hline $\log _{10}\|E E\|_{\infty}$ & -6.75093 & -7.41723 & -2.06101 \\
\hline \hline
\end{tabular}

For the PSP method, the approximated shadow prices that we obtained were

$$
\begin{aligned}
& \widetilde{\Phi}\left(z_{t}, K_{t}\right)=e^{\left(0.923-0.495 \ln \left(K_{t}\right)-0.473 z_{t}\right)} \\
& \widetilde{\Psi}\left(z_{t}, K_{t}\right)=e^{\left(1.085-0.544 \ln \left(K_{t}\right)-0.457 z_{t}\right)}
\end{aligned}
$$

which are very similar to the first-order solution presented in Ambler and Pelgrin (2010, Table $2) .6$

Comparing the solutions shown in Table 2, it is clear that the three procedures produce very similar results, at least in terms of the model's stochastic steady state. To the extent that there are differences, however, it is the PSP method whose results differ, which is consistent with the PSP method being generally less accurate and having larger Euler-equation errors. ${ }^{7}$ It should be emphasized, however, that the differences among the three solutions are minor, a finding that carries over to the unconditional densities shown in Figure 1. Indeed, looking at Figure 1, although PSP produces Euler-equation errors (panel C) that are somewhat larger than either VFI or GEE, because these errors are not particularly systematic (such as being mostly of the same sign) they largely wash-out when computing the unconditional densities (panels D-I). To the extent that differences between PSP and the other two methods are apparent, they reside chiefly in the decision rule for government spending (panel B), where it is apparent that PSP tends to understate government spending when capital is large. ${ }^{8}$

\footnotetext{
${ }^{6}$ The results that we obtain from a second-order version in which equations (33) and (34) also contain the squares of $\ln \left(K_{t}\right)$ and $z_{t}$ and the interaction between $\ln \left(K_{t}\right)$ and $z_{t}$, are very similar to those presented in Table 2 and Figure 1.

${ }^{7}$ The Euler-equation errors presented in Figure 1 differ from those presented in Ambler and Pelgrin (2010). We suspect that the source of this difference resides in the procedure used to numerically integrate the technology shock. If we simply set the technology shock to its unconditional mean when computing the Euler-equation errors, then we obtain results very similar to theirs.

${ }^{8}$ The decision rules for shown in Figure 1 (panels A and B), depict consumption and government spending, respectively, as a function of capital, holding $z_{t}=0$.
} 
A: Consumption spending

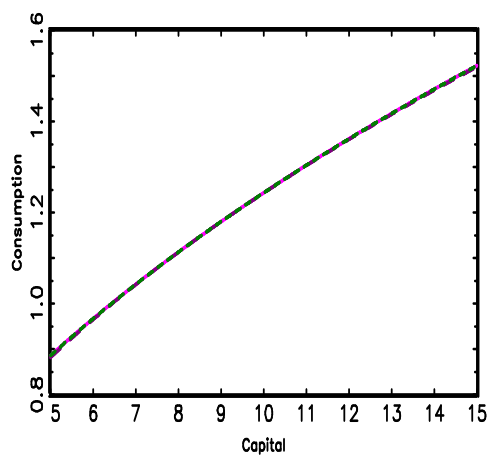

D: Consumption density
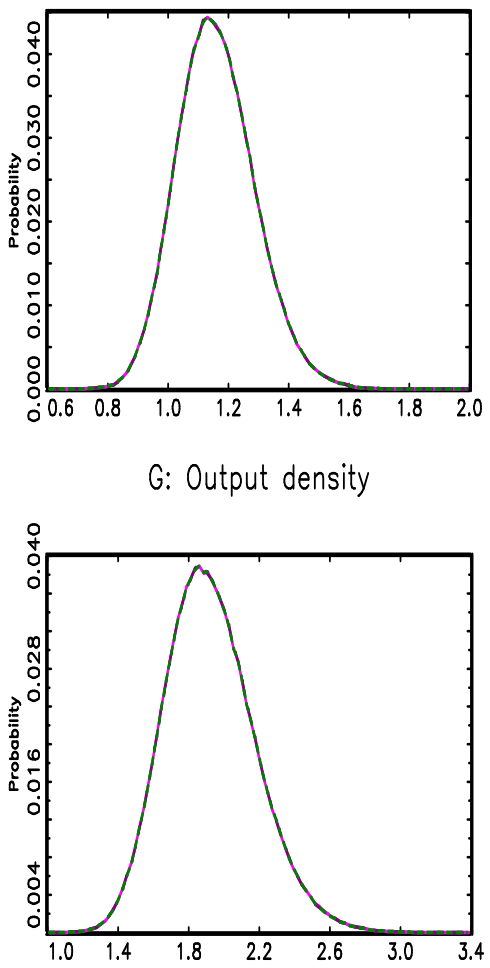

B: Government spending

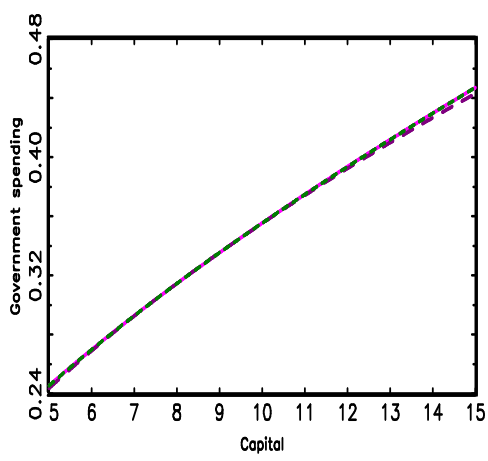

E: Government spend. density
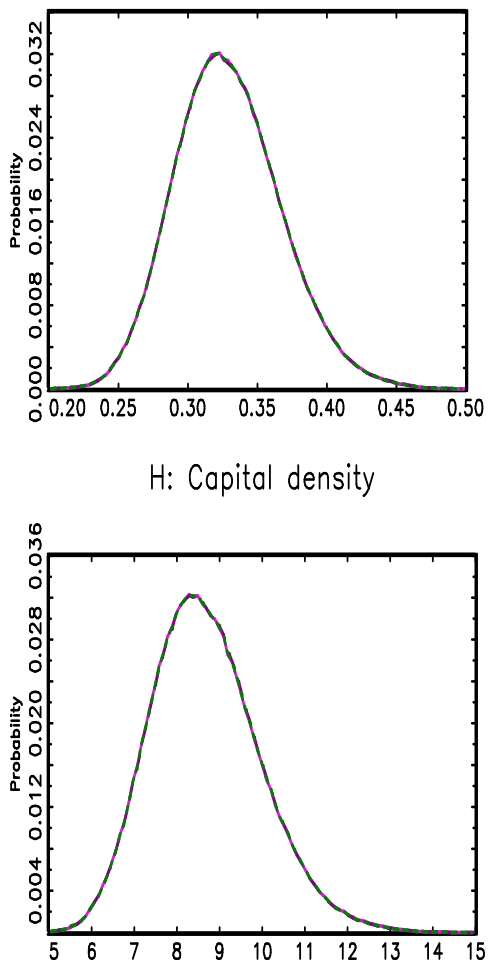

C: Euler-equation errors

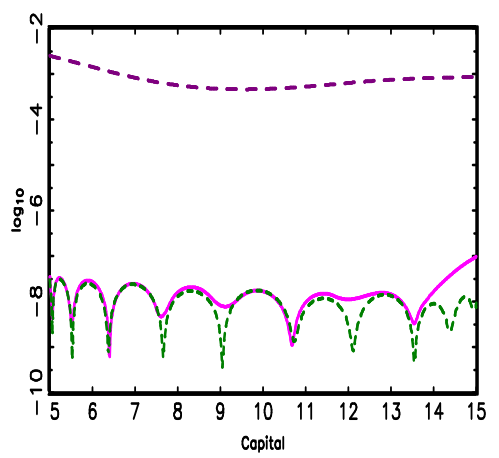

F: Investment density
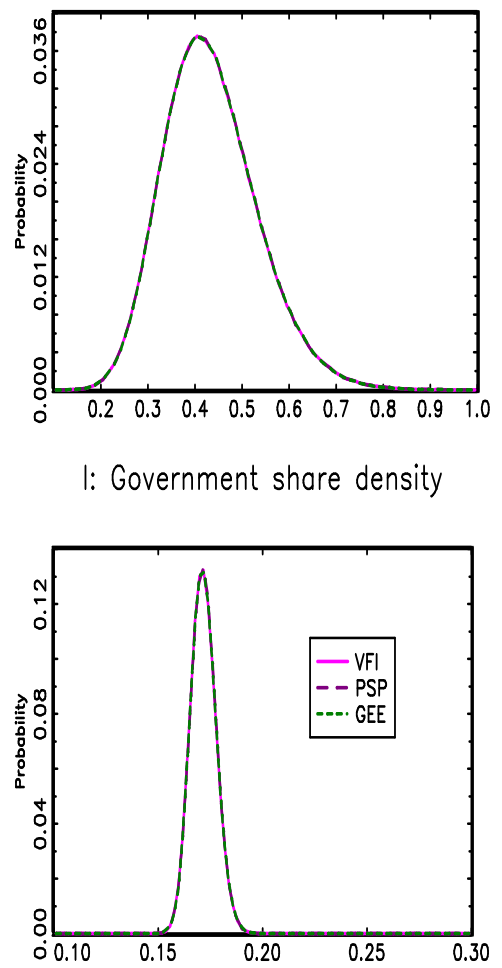

Figure 1: Comparing solutions

\subsection{The numerical accuracy of the PSP approach}

We saw in Figure 1 that the PSP solution method obtained using parameterized expectations was less accurate in terms of Euler equation errors that either GEE or VFI. To explore the reason for this decline in accuracy, we compute an alternative PSP solution (PSP-alt) in which the 
approximating function is a Chebyshev polynomial and expectations are computed using GaussHermite quadrature rather than Monte Carlo integration. For PSP-alt, therefore, we replace (33) and (34) with polynomials in the form of (30), and use the same grid as used for VFI and GEE. The results are shown in Figure 2.

$$
\text { Euler-equation errors }
$$

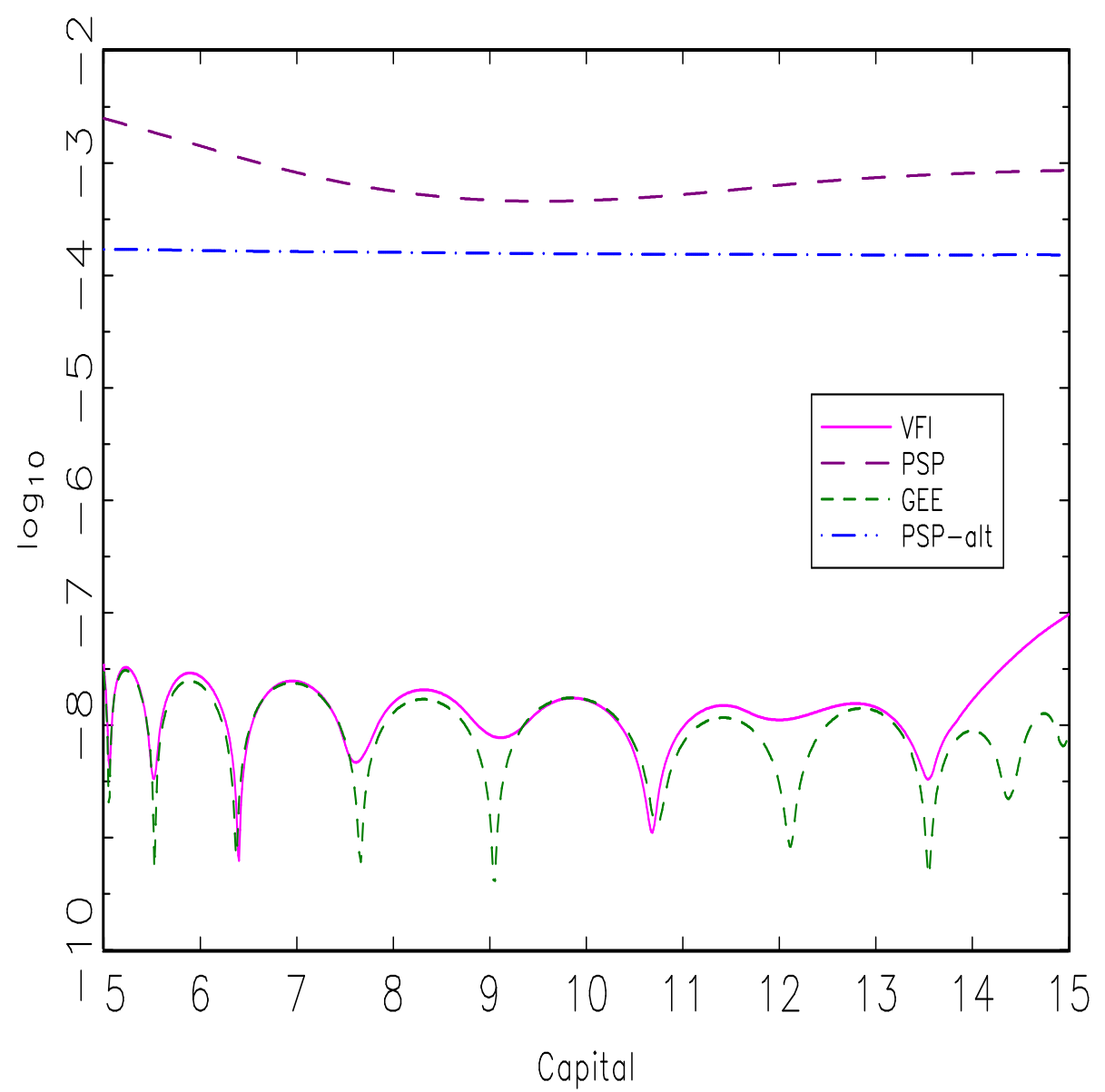

Figure 2: Numerical accuracy of PSP solution method

It is clear from Figure 2 that PSP-alt remains inferior in terms of Euler-equation accuracy than either GEE or VFI, but improves upon the benchmark PSP-solution described in Section 3.3 (which follows Ambler and Pelgrin, 2010). This implies, therefore, that the decline in numerical accuracy associated with PSP stems less from the choice of approximating function or from the 
method of integration, and more on the object being approximated. Specifically, comparing PSPalt with GEE the essential difference is that GEE approximates the decision rules for consumption and government spending whereas PSP-alt approximates convolutions of these decision rules as part of a more general function.

\section{More sophisticated policy-problems}

In this section we consider two policy problems that are more sophisticated than the benchmark model considered above. The first of these policy problems introduces a constraint on government spending (as a share of output), a constraint that is occasionally binding in that it binds in some regions of the state-space, but not in others. In many respects, this occasionally binding constraint is not unlike those that appear in monetary policy models with a zero-lower bound on the nominal interest rate or in models with occasionally binding collateral constraints. The second of these policy problems assumes that the fiscal authority is a risk-sensitive decisionmaker. We consider these two variations on the benchmark model because they each pose problems for GEE and PSP - particularly risk-sensitivity — but can be accommodated easily through VFI. In particular, although models containing inequality constraints like that described in section 5.1 can be solved using the PSP and GEE solution methods, using the techniques described in Christiano and Fisher (2000), for example, these techniques are somewhat more diffcult to implement than simply imposing box-constraints within a hill-climber, which is all that is required for VFI. In regard to models with risk-sensitive preferences, first-order methods such as GEE and PSP are generally inappropriate for such problems precisely because they do not retain the level of the value function.

\subsection{Constraints on government spending or taxes}

Using VFI it is straightforward to impose inequality constraints on government spending by employing a constrained hill-climber when optimizing the fiscal authority's value function with respect to $G_{t}$. Accordingly, if one wants to constrain government spending as a share of output, such as

$$
\kappa_{h} e^{z_{t}} K_{t}^{\alpha} \geq G_{t} \geq \kappa_{l} e^{z_{t}} K_{t}^{\alpha}
$$

where $\kappa_{h}>\kappa_{l}>0$, then one simply determines the upper and lower bound on $G_{t}$ for each node in the state space and determines $G\left(z_{t}, K_{t}\right)$ and $V\left(z_{t}, K_{t}\right)$ using constrained optimization. 
Inequality constraints on the tax rate can be similarly accommodated. For example, to constrain $\tau_{t}$ to reside in the interval $\tau_{t} \in\left[\tau_{l}, \tau_{h}\right]$, we translate this inequality constraint on the tax rate into one on government spending, as per

$$
\tau_{h}\left(e^{z_{t}} K_{t}^{\alpha}-\delta K_{t}\right) \geq G_{t} \geq \tau_{l}\left(e^{z_{t}} K_{t}^{\alpha}-\delta K_{t}\right)
$$

and then, as before, maximize the value function at each node in the state space using a constrained hill-climber.

For illustrative purposes, the model that we consider is one in which government spending is constrained to be no less than 16.5 percent of output, with this percent chosen so that the spending constraint would bind occasionally, but not predominantly. We refer to this model as the fiscally constrained model.

\subsection{Risk-sensitive preferences}

VFI can also be used to solve decision problems in which the policymaker has risk-sensitive preferences, perhaps motivated by ambiguity aversion or by an aversion to model uncertainty (Hansen and Sargent, 2008). In place of (12), a risk-sensitive fiscal authority will conduct fiscal policy based on the Bellman equation

$$
V\left(z_{t}, K_{t}\right)=\max _{G_{t}, K_{t+1}}\left[\frac{C\left(z_{t}, K_{t}, G_{t}\right)^{1-\sigma}-1}{1-\sigma}+\mu \frac{G_{t}^{1-\eta}-1}{1-\eta}+\frac{\beta}{\theta} \ln \left[\mathrm{E}_{t} e^{\left[\theta V\left(z_{t+1}, K_{t+1}\right)\right]}\right]\right],
$$

where $\theta<0$ is the risk-sensitivity parameter and the constraint continues to be given by (10). An application of L'Hôpitals' rule establishes that (12) is restored in the limit as $\theta \uparrow 0$ while the effects of $\theta<0$ are to distort the continuation value in the Bellman equation, a distortion arising from the fiscal authority's aversion to risky life-time utility. Because the value function is an object that VFI retains and delivers, risk-sensitive preferences are straightforward to analyze. To illustrate this point, and to examine the effects that risk-sensitive preferences have on Markov-perfect fiscal policy, we consider a decision problem for which the fiscal authority's Bellman equation is described by (40) with $\theta=-1.0$. We refer to this model as the risk-sensitive preferences model.

\subsection{First-best}

As a baseline against which to contrast the Markov-perfect equilibria obtained from the benchmark model, the fiscally constrained model, and the risk-sensitive preferences model, we also solve 
for the first-best equilibrium in the benchmark model. To compute this first-best equilibrium we formulate the decision problem for the fiscal authority in terms of the Bellman equation

$$
V\left(z_{t}, K_{t}\right)=\max _{\left\{C_{t}, G_{t}, K_{t+1}\right\}}\left[\frac{C^{1-\sigma}-1}{1-\sigma}+\mu \frac{G_{t}^{1-\eta}-1}{1-\eta}+\beta \mathrm{E}_{t}\left[V\left(z_{t+1}, K_{t+1}\right)\right]\right],
$$

with the constraint given by (10) and with technology evolving according to (4). Although there are two choice variables, this is a standard dynamic programming problem and can be solved using the VFI strategy described above. For the benchmark model, the first-best equilibrium must satisfy the resource constraint

$$
K_{t+1}=(1-\delta) K_{t}+e^{z_{t}} K_{t}^{\alpha}-C_{t}-G_{t}
$$

and the first-order conditions

$$
\begin{aligned}
C_{t}^{-\sigma} & =\beta \mathrm{E}_{t}\left[C_{t+1}^{-\sigma}\left(1-\delta+\alpha e^{z_{t+1}} K_{t+1}^{\alpha-1}\right)\right], \\
C_{t}^{-\sigma} & =\mu G_{t}^{-\eta} .
\end{aligned}
$$

We use (43) to construct the Euler-equation errors in our accuracy test, which, because it is not imposed in obtaining the solution, leads to a relatively stringent test of accuracy.

\subsection{Results}

In this section we solve for the Markov-perfect equilibrium of the benchmark model, the fiscally constrained model, and the risk-sensitive preferences model. We contrast these equilibria with the first-best equilibrium obtained from the benchmark model. Table 3 and Figure 2 contain a summary of the main results. The "deterministic" steady state results shown in Table 3 correspond to the steady state in a Markov-perfect equilibrium of a deterministic version of the benchmark model. However, because risk-sensitivity generates no risk-adjustment when the model is deterministic and because the government spending constraint that we impose in the fiscally constrained model does not bind at the deterministic steady state, the deterministic steady state values reported apply equally to the fiscally constrained model and to the risk-sensitive preferences model. 


\begin{tabular}{l|c|c|c|c|c}
\hline \hline \multicolumn{7}{c}{ Table 3: Steady state solutions and numerical accuracy } \\
\hline \multicolumn{1}{c}{ Variable } & Deterministic & Benchmark & Fiscally const. & Risk-sensitive & First-best \\
\hline Output & 1.90236 & 1.92262 & 1.9223076 & 1.92869 & 1.96881 \\
Consumption & 1.15008 & 1.15960 & 1.1587733 & 1.19650 & 1.15329 \\
Government spend. & 0.32575 & 0.32907 & 0.3298144 & 0.29366 & 0.34599 \\
Investment & 0.42653 & 0.43396 & 0.4337198 & 0.43853 & 0.46953 \\
Capital & 8.53053 & 8.67923 & 8.6744408 & 8.77060 & 9.39064 \\
\hline $\log _{10}\|E E\|_{\infty}$ & -7.46797 & -6.75093 & -4.97567 & -7.03006 & -4.75445 \\
\hline \hline
\end{tabular}

Table 3 shows that the deterministic steady state for capital is just over 8.53. Allowing for stochastic aggregate technology, as per the benchmark model, the (stochastic) steady state for capital rises to about 8.68. This rise in steady-state capital occurs through a standard precautionary saving motive whereby risk-averse households increase their saving and accumulate capital as a buffer to self-insure against adverse technology shocks. Consistent with a higher steady state capital stock, the steady state values for output, consumption, and investment are all higher in the benchmark model than they are in its deterministic counterpart.

The constraint that government spending as a share of output be no smaller than 0.165 has little effect on the model's stochastic steady state, which is very similar to that of the benchmark model, but it does lead to a decline in numerical accuracy. Nonetheless, with the $\log _{10}$ of the maximum Euler-equation error at about -5 the maximal solution error amounts to about one dollar out of every one hundred thousand dollars spent, which certainly seems acceptable. Comparing the benchmark model to the risk-sensitive preferences model, it is clear that the fiscal authority's risk-sensitivity is having a profound effect on fiscal policy. Specifically, at the (stochastic) steady state the risk-sensitive fiscal authority chooses less government spending than does the fiscal authority in the benchmark model. With less government spending the risk-sensitive fiscal authority also imposes a smaller income tax rate, reducing some of the disincentive households's face to accumulate capital. As a consequence, the (stochastic) steady state for capital in the risk-sensitive preferences model is almost 8.8, somewhat higher than in the benchmark model. Table 3 also presents summary statistics for the first-best equilibrium, quantifying the effects of distortionary taxation and the time-inconsistency problem that these distortions produce. 
A: Consumption spending

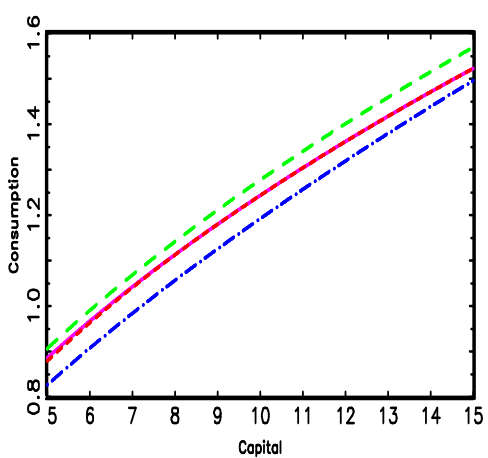

D: Consumption density

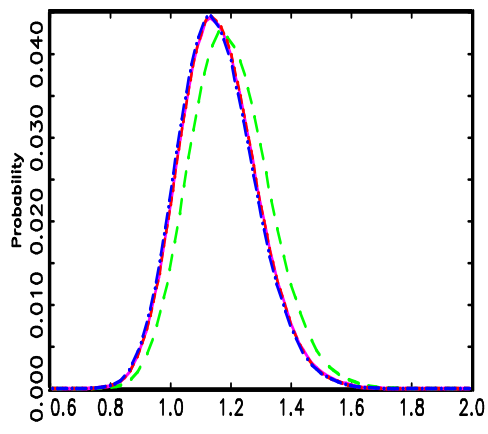

G: Output density

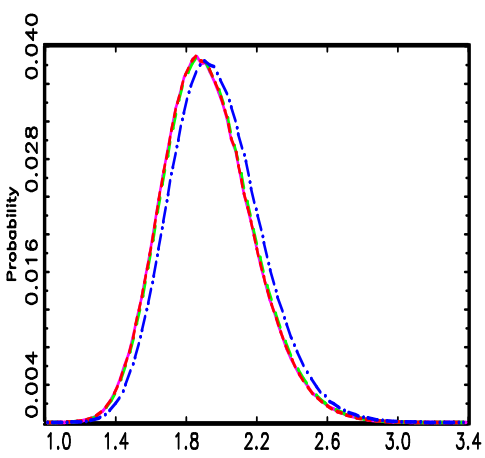

B: Government spending

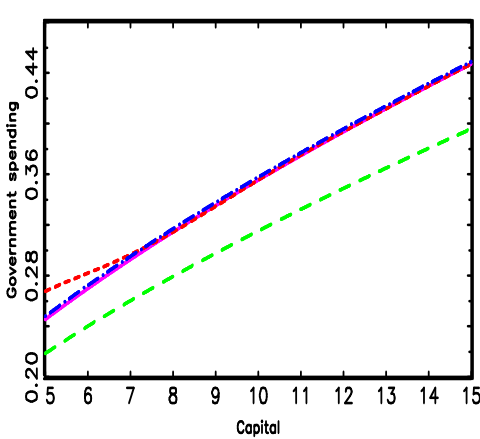

E: Government spend. density

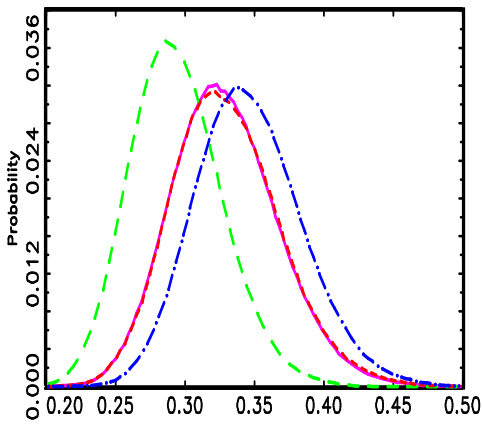

H: Capital density

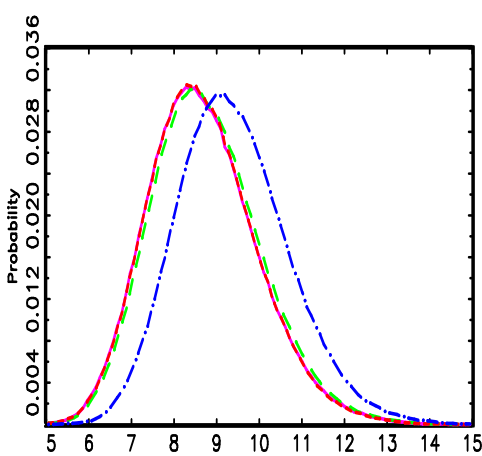

C: Euler-equation errors

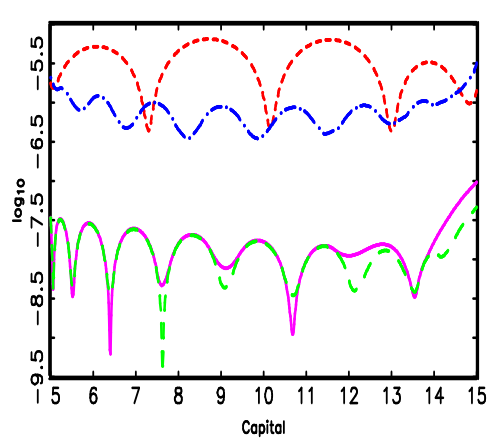

F: Investment density

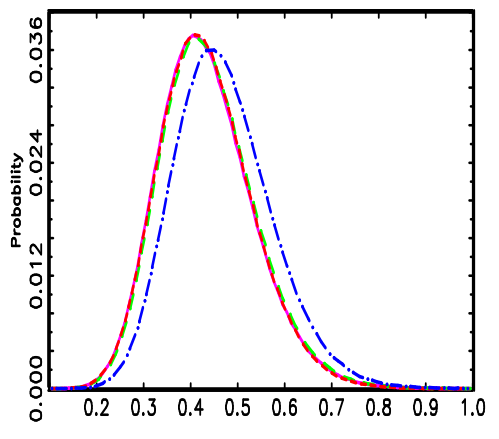

I: Government share density

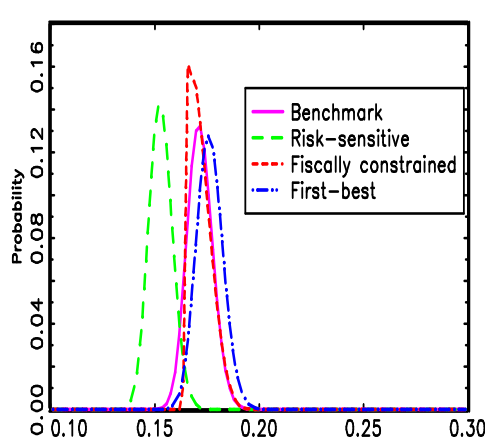

Figure 3: Solution and accuracy

Where Table 3 presents information about steady state outcomes, Figure 3 presents the consumption function, the government spending function, the densities of the key model-variables, and additional information about numerical accuracy. As earlier, we construct the densities by simulating data from each solution, we report the decision rules for consumption and government spending holding $z_{t}=0$, and we use (35) to compute the Euler-equation errors (suitably modified 
in the case of the first-best equilibrium).

Perhaps unsurprisingly, the consumption functions for the benchmark model and the fiscally constrained model are very similar. The differences between these two models are reflected more prominently in their respective government spending functions, where the constraint on government spending binds occasionally to force higher government spending in the fiscally constrained economy. The effects of risk-sensitivity are evident in both the consumption function and the government spending function. Because the risk-sensitive fiscal authority is especially concerned about risk, she wishes households to build up a buffer-stock of capital, keeping government spending and hence income taxes low in order to encourage households to do so. Of course, the income effect associated with the lower lifetime tax liability (the model is Ricardian) induces households to also consume more, leading households to consume more in the risk-sensitive model relative to the benchmark model.

Interestingly, each of the models produces similar densities for output and, to a lesser extent, for consumption. The four models differ importantly, however, with respect to the densities for investment, capital, government spending, and government spending as a share of output. With distortionary taxes, government spending is too low, both in absolute terms and as a share of output, relative to the first-best equilibrium. The constraint on government spending in the fiscally constrained economy is evident in the density for government spending as a share of output, but has relatively little effect on the density for government spending itself.

Having shown the densities for output, consumption, etc, in Figure 3, Figure 4 presents the impulse response functions for the key model variables following a positive one standard deviation technology shock; Figure 5 displays analogous responses, but for a negative one standard deviation technology shock. Looking at Figure 4, there are notable differences in how the various model's respond, particularly in regard to government spending and consumption. In the fiscally constrained economy, with output rising in response to the technology shock the constraint on government spending binds pushing up government spending at the expense (primarily) of lower private consumption. At the same time, interestingly, the benchmark equilibrium, the risksensitive equilibrium, and the first-best equilibrium respond similarly to the shock. 
A: Output

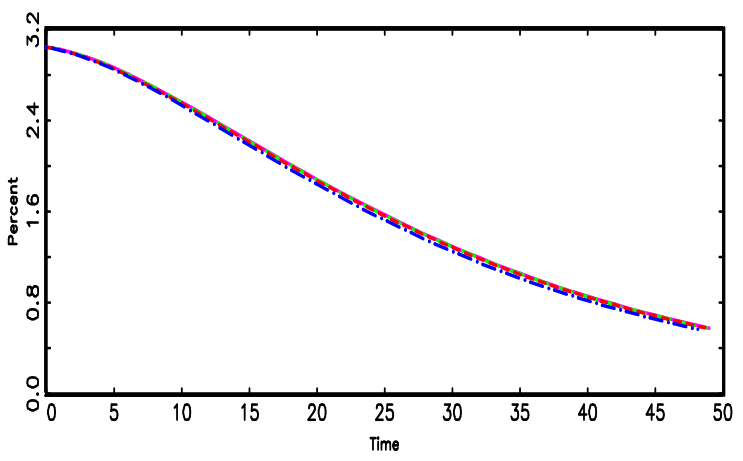

C: Government spending

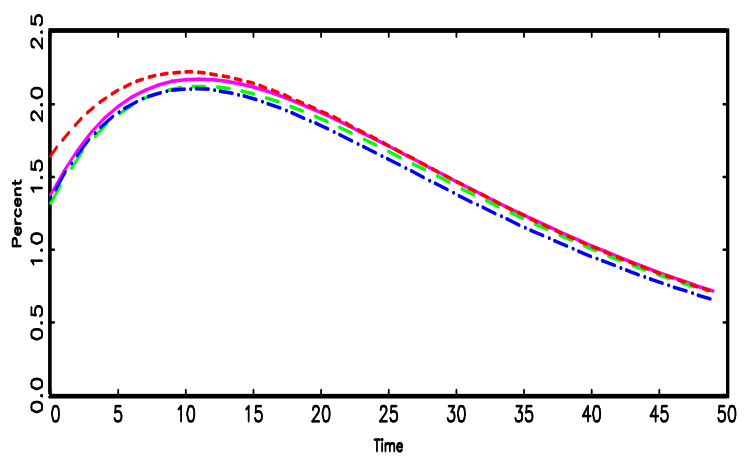

E: Capital

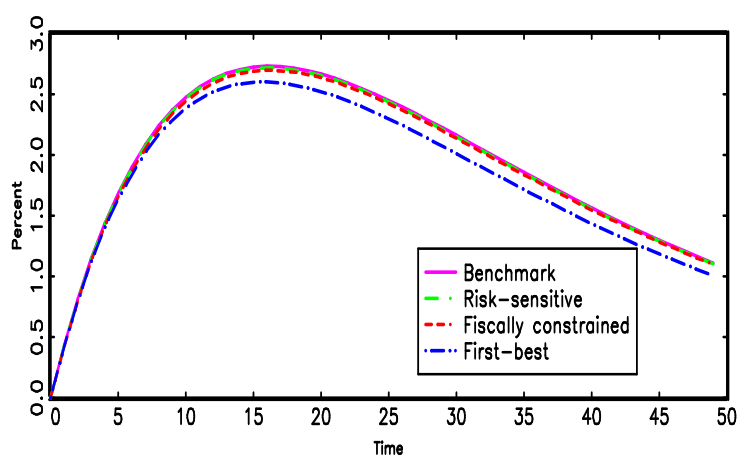

B: Consumption

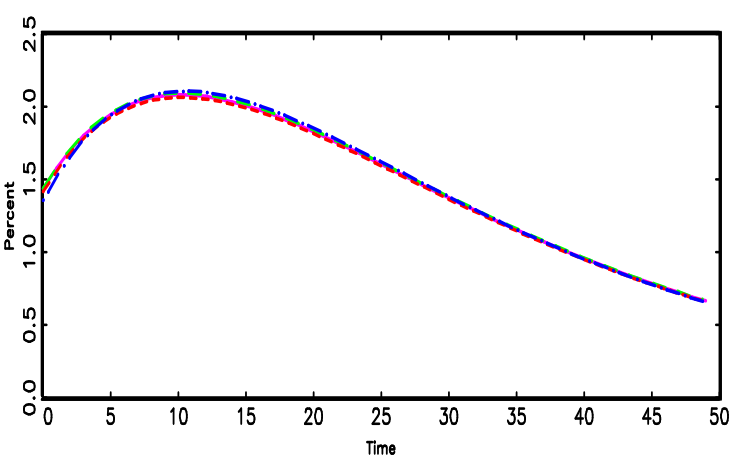

D: Investment

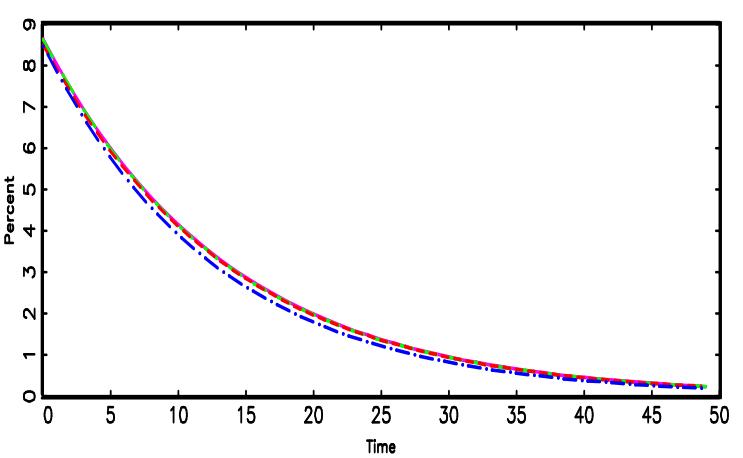

Figure 4: Responses to a positive 1 s.d. technology shock

In response to a negative technology shock, Figure 5 reveals some asymmetries relative to the responses to a positive shock shown in Figure 4. In particular, unlike a positive technology shock, the constraint on government spending does not bind following a negative technology shock and there are greater differences between the first-best equilibrium and the benchmark model. Other than for the fiscally constrained economy, for which there is a clear asymmetry in the government 
spending response, the models' responses are relatively symmetric
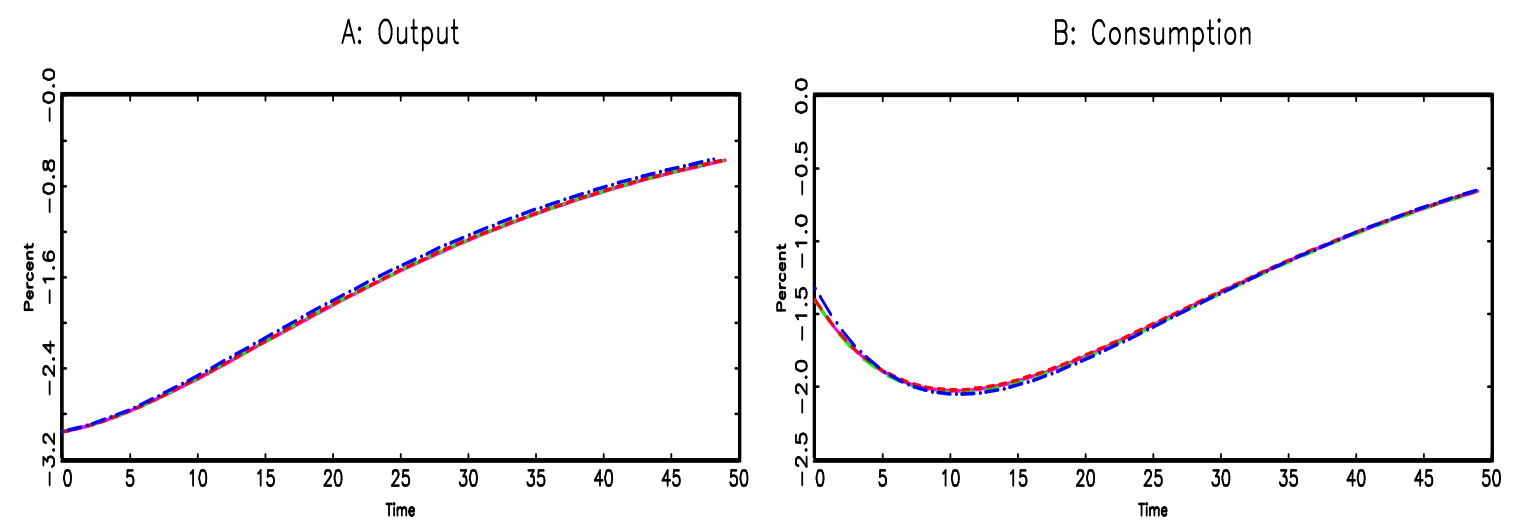

C: Government spending

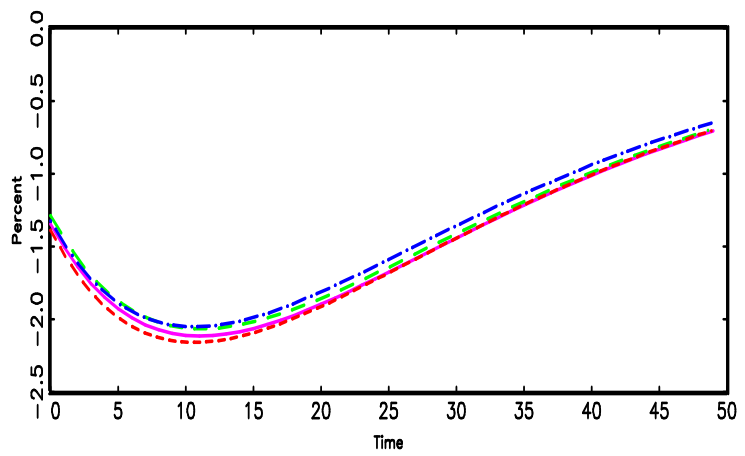

D: Investment

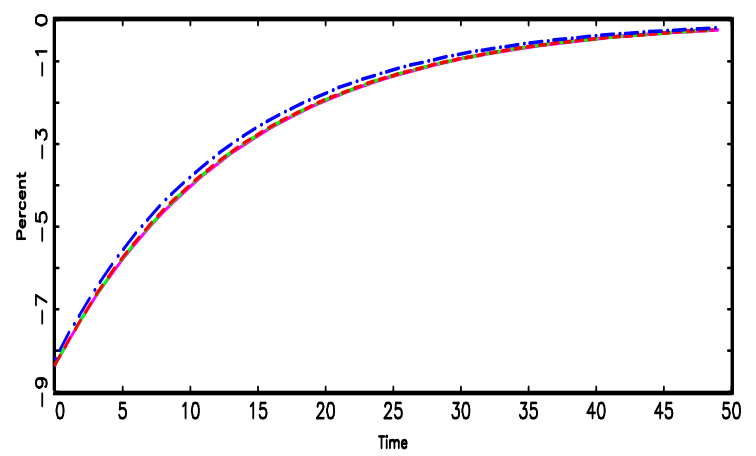

E: Capital

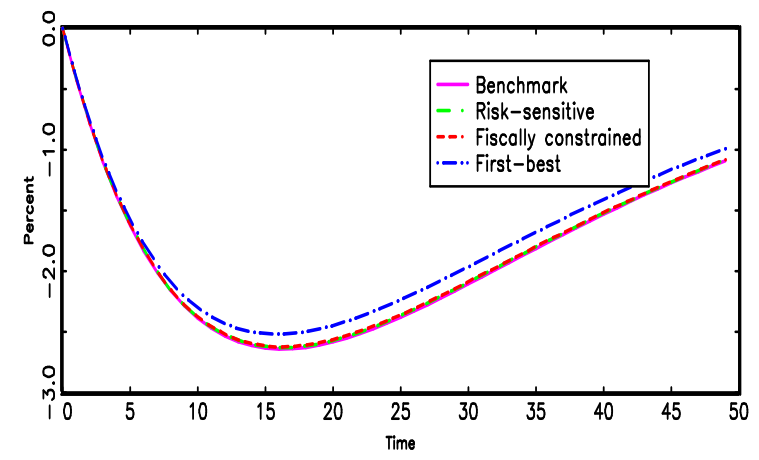

Figure 5: Responses to a negative 1 s.d. technology shock

To better identify asymmetries in the impulse response functions we plot in Figure 6 the sum of the responses to the positive and negative shock for each variable. To the extent that each model is asymmetric the sum of the responses differs from zero. Looking at Figure 6 (panel E) we see a notable asymmetry in the capital stock's reponses to technology shocks, with this asymmetry 
propagated through capital role as a state variable into the remaining variables. In addition to this asymmetry, Figure 5 also reveals the asymmetries present in the fiscally constrained economy and shows how the occasionally binding constraint on government spending induces asymmetric behavior in consumption and investment.

A: Output

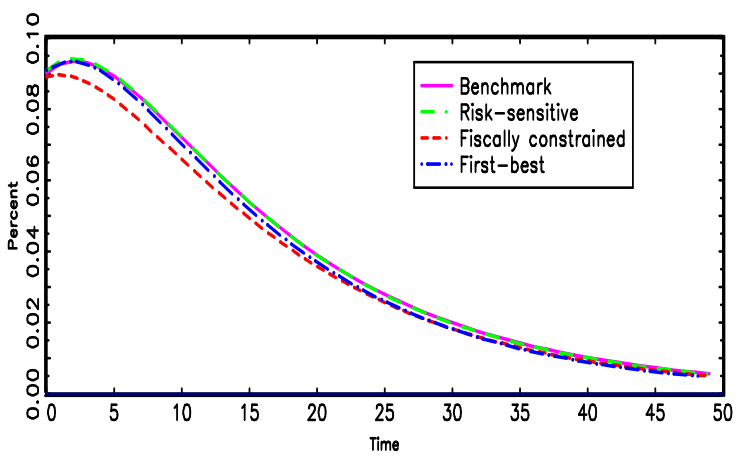

C: Government spending

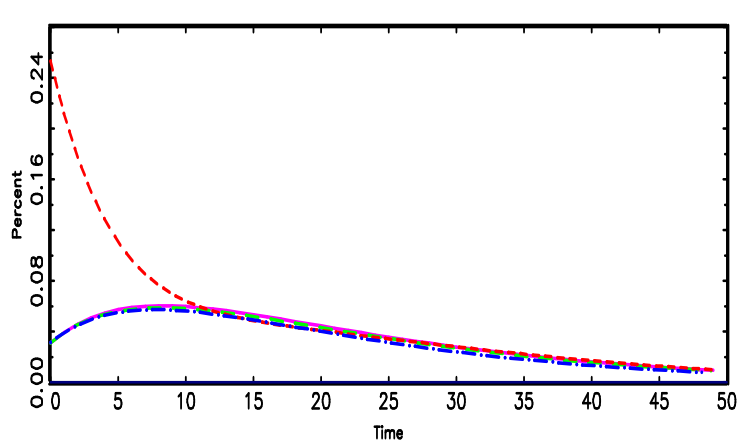

E: Capital

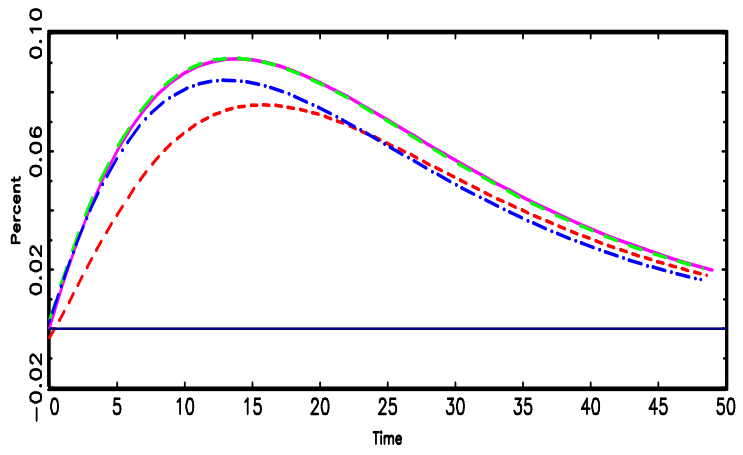

B: Consumption

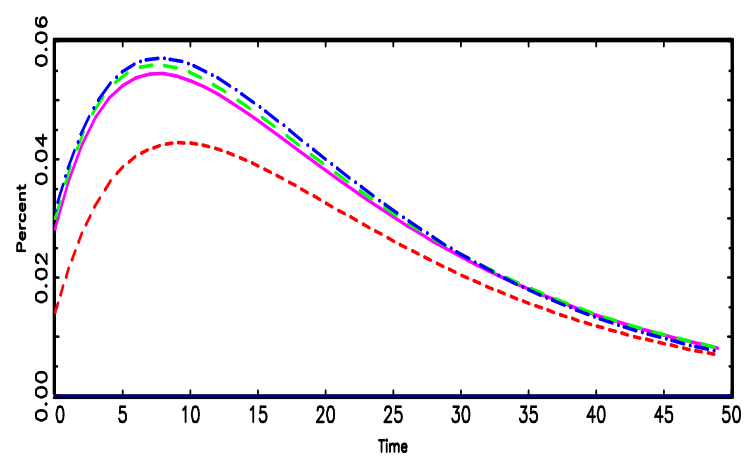

D: Investment

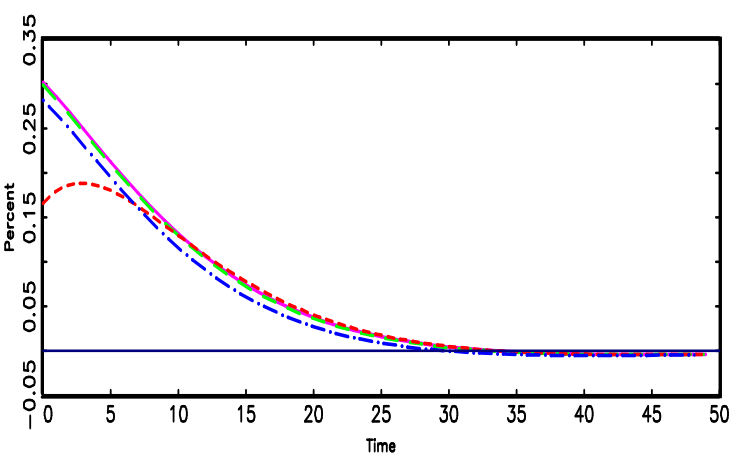

Figure 6: Impulse response asymmetries 


\section{Discussion}

The models solved above are relatively small in that they contain only one endogenous state variable and one shock. With only two state variables and the need to integrate over a single shock these models can be solved relatively quickly by all three methods, although with varying accuracy. Excluding coding time, which is an important consideration, GEE and PSP-alt were the quickest, followed by VFI and then PSP. ${ }^{9}$ However, each of these methods suffers from the curse of dimensionality. As a consequence, solving larger models, ones containing a handful of state variables or more, can be very time-consuming. For such models, it may be advantageous to employ complete polynomials rather than tensor-product polynomials or to use sparse-grid methods (Smolyak, 1963), as described in Malin, Krueger, and Kubler (2011), for example, or monomial-methods (Pichler, 2011).

\section{Conclusion}

This paper has presented and compared three methods for computing Markov-perfect optimal policies in nonlinear business cycle models. Of these methods, two were based on Euler equations while the third was based on value function iteration. We illustrated these solution methods by applying them to a canonical business cycle model of government-good provision in which a fiscal authority must determine optimally the provision of government goods, subject to distortionary taxation, a balanced-budget constraint, and while lacking a commitment technology. For this benchmark model we found that all three methods worked well, that the use of generalized Euler equations and value function iteration gave essentially identical results, and that the parameterized shadow price method was the less accurate of the three. We further showed that the value function iteration solution method could easily be extended to accommodate model features such as risk-sensitive preferences and certain forms of occasionally binding constraints, such as bounds on government spending or the tax rate.

Although our application focused on fiscal policy, many economic decision problems can be tackled using the solution procedures described in this paper. In particular, problems relating to monetary policy design, both with and without a zero-bound on nominal interest rates, monetary

\footnotetext{
${ }^{9}$ This ordering simply reflects our experience with these methods, without attempting to optimize them for speed. A comprehensive study of solution times, one that optimized the solution methods, conditioned them upon identical initial conditions (to the extent possible), and the requirement that they produce the same level of accuracy, is beyond the scope of this paper.
} 
and fiscal policy coordination, exchange rate management, and international lending. These solution procedures can also be used to examine the effects of risk-sensitivity on allocations and asset prices in economies where policymakers cannot commit.

\section{References}

[1] Adam, Klaus, and Roberto Billi (2007) Discretionary monetary policy and the zero-bound on nominal interest rates. Journal of Monetary Economics 54, 728-754.

[2] Ambler, Steve, and Florin Pelgrin (2010) Time-consistent control in nonlinear models. Journal of Economic Dynamics and Control 34, 2215-2228.

[3] Anderson, Gary, Jinill Kim, and Tack Yun (2010) Using a projection method to analyze inflation bias in a micro-founded model. Journal of Economic Dynamics and Control 34, $1572-1581$.

[4] Backus, David, and John Driffill (1986) The consistency of optimal policy in stochastic rational expectations models. Centre for Economic Policy Research Discussion Paper \#124.

[5] Benhabib, Jess, and Aldo Rustichini (1997) Optimal taxes without commitment. Journal of Economic Theory 77, 231-259.

[6] Benveniste, Lawrence, and Jose Scheinkman (1979) On the differentiability of the value function in dynamic models of economies. Econometrica 47, 727-732.

[7] Christiano, Lawrence, and Jonus Fisher (2000) Algorithms for solving dynamic models with occasionally binding constraints. Journal of Economic Dynamics and Control 24, 1179-1232.

[8] Clarida, Richard, Jordi Galí, and Mark Gertler (1999) The science of monetary policy: a new keynesian perspective. Journal of Economic Literature 37, 1661-1707.

[9] Cohen, Daniel, and Philippe Michel (1988) How should control theory be used to calculate a time-consistent government policy. Review of Economic Studies LV, 263-274.

[10] Currie, David, and Paul Levine (1985) Macroeconomic policy design in an interdependent world. In Willem Buiter and Richard Marston (eds), International Economic Policy Coordination, pp. 228-273.

[11] Currie, David, and Paul Levine (1993) Rules, Reputation and Macroeconomic Policy Coordination, Cambridge: Cambridge University Press.

[12] Dennis, Richard (2007) Optimal policy in rational expectations models: new solution algorithms. Macroeconomic Dynamics 11, 31-55.

[13] Domínguez, Begõna (2007) Public debt and optimal taxes without commitment. Journal of Economic Theory 135, 159-170.

[14] Hansen, Lars, and Thomas Sargent (2008) Robustness. Princeton, NJ: Princeton University Press.

[15] Inada, Ken-Ichi (1963) On a two-sector model of economic growth: comments and a generalization. Review of Economic Studies 30, 119-127. 
[16] Judd, Kenneth (1992) Projection methods for solving aggregate growth models. Journal of Economic Theory 58, 410-452.

[17] Klein, Paul, Per Krusell, and Jose-Victor Rios-Rull (2008) Time-consistent public policy. Review of Economic Studies 75, 789-808.

[18] Klein, Paul, and Jose-Victor Rios-Rull (2003) Time-consistent optimal fiscal policy. International Economic Review 44, 1217-1245.

[19] Kydland, Finn, and Edward Prescott (1977) Rules rather than discretion: the inconsistency of optimal plans. Journal of Political Economy 85, 473-491.

[20] Malin, Benjamin, Dirk Krueger, and Felix. Kubler (2011) Solving the multi-country real business cycle model using a Smolyak-collocation method. Journal of Economic Dynamics and Control 35, 229-239.

[21] Marcet, Albert, and Guido Lorenzoni (1999) The parameterized expectations approach: some practical issues. In Ramon Marimon and Andrew Scott (eds), Computational Methods for the Study of Dynamic Economies, pp. ??-??.

[22] Martin, Fernando (in press) Policy and welfare effects of within-period commitment. Macroeconomic Dynamics.

[23] Nakata, Taisuke (2012) Optimal fiscal and monetary policy with occasionally binding zerobound constraints. Manuscript (version dated January 12, 2012).

[24] Niemann, Stefan, Paul Pichler, and Gerhard Sorger (2008) Optimal fiscal and monetary policy without commitment. Manuscript (version dated June 16, 2008).

[25] Niemann, Stefan, Paul Pichler, and Gerhard Sorger (2009) Inflation dynamics under optimal discretionary fiscal and monetary policies, Manuscript (version dated December 17, 2009).

[26] Ortigueira, Salvador (2006) Markov-perfect optimal taxation. Review of Economic Dynamics $9,153-178$.

[27] Ortigueira, Savador, Joana Pereira, and Paul Pichler (2012) Markov-perfect optimal fiscal policy: the case of unbalanced budgets. Manuscript (version dated October 29, 2012).

[28] Oudiz, Gilles, and Jeffrey Sachs (1985) International policy coordination in dynamic macroeconomic models. In Willem Buiter and Richard Marston (eds), International Economic Policy Coordination, pp. 274-330.

[29] Pichler, Paul (2011) Solving the multi-country real business cycle model using a monomial rule galerkin method. Journal of Economic Dynamics and Control 35, 240-251.

[30] Smolyak, Sergey (1963) Quadrature and interpolation formulas for tensor products of certain classes of functions. Soviet Mathematics Doklady 4, 240-243.

[31] Söderlind, Paul (1999) Solution and estimation of RE macromodels with optimal policy. European Economic Review 43, 813-823.

[32] Stockman, David (2001) Balanced-budget rules: welfare loss and optimal policies. Review of Economic Dynamics 4, 438-459.

[33] Woodford, Michael (2003) Interest and Prices: Foundations of a Theory of Monetary Policy. Princeton, NJ: Princeton University Press. 